\title{
Splenic cyst
}

\author{
DZUNG ANH PHAM, DO \\ ANDY NGUYEN DO DUY, MD
}

The authors describe a patient who had a benign, secondary splenic cyst definitively diagnosed preoperatively by use of a computed tomography scan. Because it was not possible to distinguish between a primary and secondary nonparasitic cyst preoperatively, the treatment of choice was elective splenectomy. This procedure allows confirmation of the clinical diagnosis and involves low morbidity and mortality.

(Key words: Splenic cyst, computed tomography)

A cyst of the spleen is rare in both pathology and occurrence. This type of cyst can be classified as parasitic (malignant) and nonparasitic (benign) cysts. Fowler ${ }^{1}$ classifies a nonparasitic benign splenic cyst as a primary cyst when epithelial cellular lining is present and as a secondary cyst when no epithelial cellular lining is present. Most clinicians follow Martin's ${ }^{2}$ simplified clinical classification of a benign splenic cyst (Table).

More than two thirds of the splenic cysts seen throughout the world are parasitic hydatid cysts caused by Taenia echinococcus. ${ }^{3}$ Such cysts, however, are extremely rare in the United States. ${ }^{4}$ The neoplastic group consists of dermoid, epidermoid, lymphangiomatous, and hemangiomatous categories. In large studies, false cysts are more common than nonparasitic true cysts, ${ }^{2}$ and hemangioma is the most common primary cyst and dermoid is the rarest..$^{5,6}$

It has long been observed that trauma is the

From the College of Osteopathic Medicine of the Pacific (COMP), Pomona, Calif, where, at the time this article was written, Dr Pham was a senior medical student. Dr Duy is clinical assistant professor of surgery at COMP, Pomona, and at the University of California School of Medicine, Irvine, Calif. Dr Pham is currently in family practice residency at Kern Medical Center, Bakersfield, Calif.

Reprint requests to Dzung Anh Pham, DO, Kern Medical Center, 1830 Flower St, Bakersfield, CA 93305.

most consistent etiologic factor. An impact can cause a tear in deep-seated vessels without injuring the capsule. This tear leads to subcapsular hematoma from which a false capsule is formed. The contents of this capsule then undergoes degenerative changes. This same sequence occurs in other causes of splenomegaly, such as malaria, syphilis, tuberculosis, typhoid fever, infectious mononucleosis, leukemia, and schistosomiasis. ${ }^{7}$

In contrast, some authors ${ }^{8,9}$ believe that trauma is not the primary cause. Fowler ${ }^{10}$ suggested that the cyst represents an embryologic inclusion of peritoneum within the splenic substance. Others ${ }^{4,11}$ have suggested that a traumatic peritoneal inclusion might explain the calcification of splenic cysts. Because splenic cysts occur more frequently in women aged 20 to 40 years, hormonal influences are theoretically related both to the cyclic enlargement of the spleen during the menstrual period and to the greater incidence of intrasplenic hemorrhage after minor physical insults during pregnancy. ${ }^{12}$

\section{Report of case}

A 54-year-old white man was seen at the Fountain Valley Regional Hospital emergency room because of vague abdominal pain that had been increasing in intensity during the previous 5-day period. He denied having nausea, vomiting, diarrhea, or fever. He stated that he was hungry and that he had not eaten for

\section{Table \\ Martin's ${ }^{2}$ Simplified Classification of Benign Splenic Cyst}

I. Primary (or true) cyst - with cellular lining

A. Parasitic

B. Nonparasitic

1. Congenital

2. Neoplastic

II. Secondary (or false) cyst - without cellular lining 


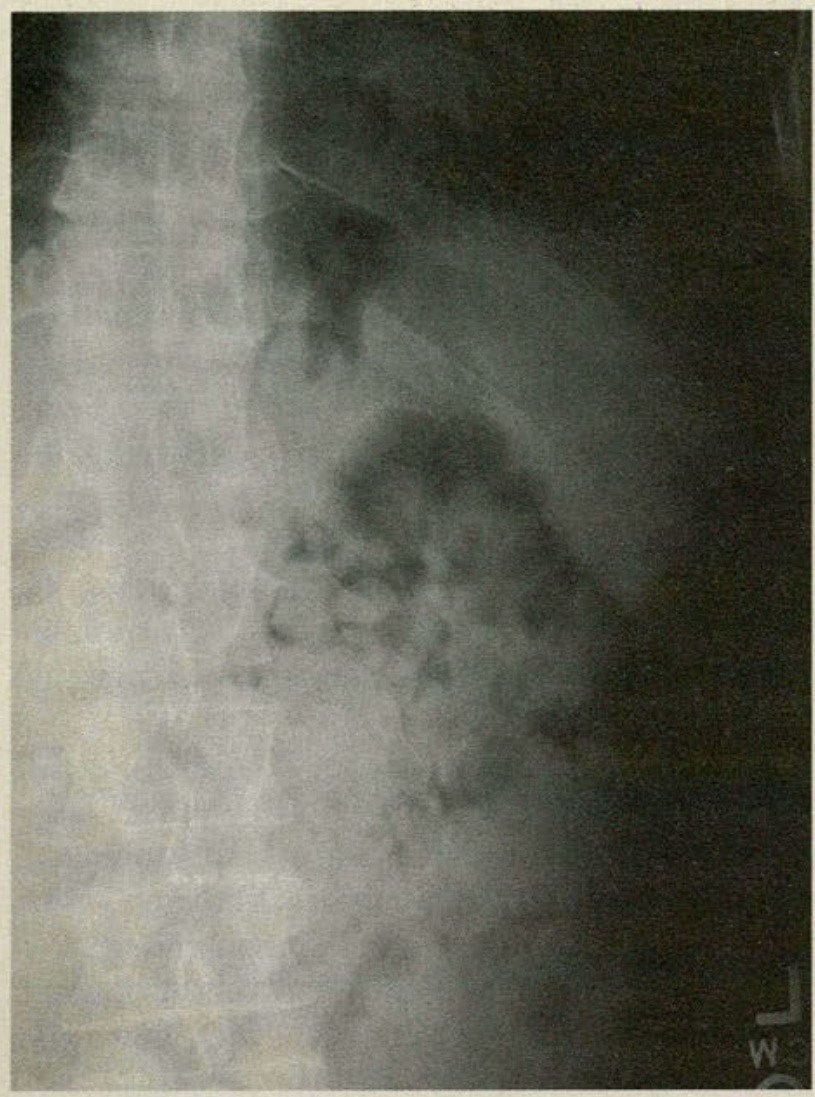

Figure 1. Abdominal $x$-ray film shows a calcified rim of splenic cyst.

the past 12 hours. The patient's medical history was significant for chronic obstructive pulmonary disease, an automobile accident in 1964 in which he did not sustain an injury although his car flipped over, and a cervical fracture resulting from a diving accident in 1968 that left him paralyzed for 1 year, at which time he was able to walk with the aid of a cane. $\mathrm{He}$ denied any history of previous infection, weight loss, jaundice, or travel out of state. He was not currently taking any medication.

On physical examination, there was guarding and diffuse abdominal pain, no abdominal distention, no bruits, and no palpable mass. Except for a slightly elevated white blood cell count $\left(13,500 / \mathrm{mm}^{3}\right)$ and a temperature of $100^{\circ} \mathrm{F}$, results of laboratory studies (complete blood cell count, Sequential Multiple Analysis 20 , urinalysis) were essentially within normal limits. The electrocardiogram showed no abnormality. The stool guaiac test was negative. Barium enema studies showed no abnormality, and the abdominal x-ray film and ab-

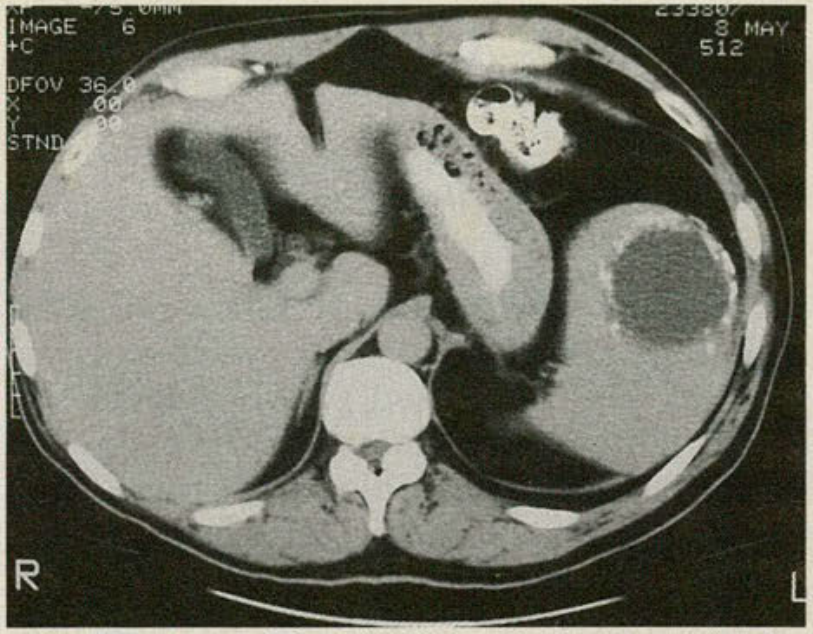

Figure 2. Abdominal computed tomography scan shows a calcified splenic cyst.

dominal CT scan showed no abnormality except for an incidental finding of a $6.3-\mathrm{cm}$ rim calcified cyst of the spleen (Figures 1 and 2).

The patient was observed for possible acute abdomen, but the pain subsided and he had no more abdominal guarding the next day. Both the white blood cell count and temperature returned to within normal limits. The patient was informed that he had a splenic cyst, and complications, treatment, and prognosis were explained to him. He elected to undergo splenectomy 1 month later.

A laparotomy was done with a subcostal incision. There were adhesions around the splenicdiaphragmatic area that made the dissection extremely difficult. The cyst, located at the superior posterior aspect of the spleen, was delivered and excised. The specimen weighed 358 g and measured $12.0 \times 9.6 \times 6.0 \mathrm{~cm}$. On one surface, there was a yellow-tan nodule measuring $7.2 \times 7.0 \mathrm{~cm}$ (Figure 3 ). Hemisection of the cyst revealed yellow-tan mucoid debris within the lumen. On microscopic examination, there was splenic parenchymal preservation of red and white pulps with congestion of the red pulp only. There were cholesterol clefts, giant cells, foamy macrophages, and cuboidal cells focally lining the calcified cyst wall. There was no evidence of any parasitic form or hamartoma. The final pathologic diagnosis was benign cyst with calcification of the wall.

The patient tolerated the operation well; how- 
ever, on the second postoperative day, right lower lobe pleural effusion, atelectasis, infiltrates, and adynamic ileus developed. The patient was given antibiotic prophylactic therapy for Pneumococcus species infection, abdominal decompression, and respiratory therapy. He was discharged from the hospital after the tenth postoperative day.

\section{Discussion}

The histologic findings of cholesterol clefts, giant cells, and foamy macrophages in our patient all implicate trauma as the primary cause. The lack of hemosiderin can be explained by tissue reabsorption over a long period.

Splenic cysts can be asymptomatic ${ }^{4,10}$ or can be manifested as an acute abdomen, as in the patient described herein. Frequently, patients complain of left upper quadrant pain, enlarged abdomen, and a palpable mass. Pain can radiate to the left side of the neck, left shoulder, and left arm. Splenic cyst can be associated with hypertension by renal compression. ${ }^{13}$

The differential diagnosis of left upper quadrant mass should include the liver, kidney, adrenal gland, and stomach. The clinician should also check the patient for cystic lesion, pancreatic tumor, retroperitoneal tissues, and splenic flexure of the colon.

Because only $10 \%$ of all splenic cysts reported in the world medical literature are visible on plain abdominal films and chest $\mathrm{x}$-ray films, further roentgenographic studies are needed. Frequently, barium enema, intravenous pyelography, and upper gastrointestinal studies will demonstrate splenomegaly, but these studies are inconclusive for establishing the diagnosis of a benign splenic cyst. Computed tomography scans, ${ }^{14}$ percutaneous selective abdominal angiography, ${ }^{15}$ and ultrasound ${ }^{14,16}$ have been used for a definite diagnosis. If echinococcal cyst of the spleen can be ruled out with cutaneous skin tests, complement fixation, and precipitation tests, percutaneous needle aspiration can be attempted for diagnosis ${ }^{17,18}$ and therapy. ${ }^{19}$ Within the nonparasitic splenic cyst group, reliable radiologic distinction between true and false splenic cyst does not seem possible. Furthermore, the

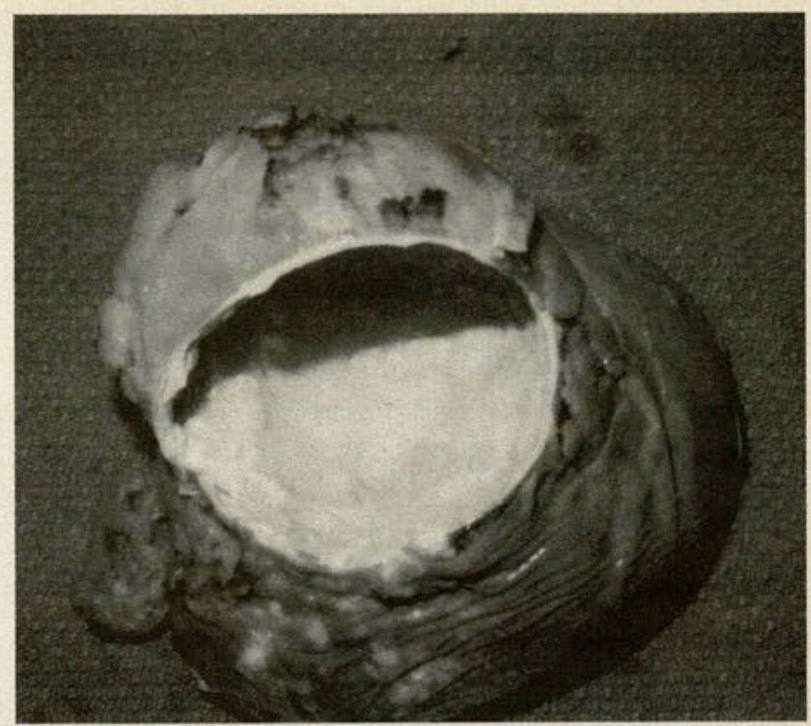

Figure 3. Gross specimen of splenic cyst with yellowtan nodule removed.

history and clinical presentations including pain, splenomegaly, and mass is similar in patients with both types of cysts. ${ }^{14}$

The success of surgical intervention for hydatid cyst depends on proper diagnosis of the number, location, and size of the cyst(s). Surgical rupture of the cyst may cause anaphylactic shock or secondary echinococcosis unless its contents are sterilized with $15 \%$ or $20 \%$ hypertonic solution. ${ }^{20}$ When surgery is contraindicated or cysts rupture spontaneously during surgery, mebendazole can be tried. ${ }^{21}$

Splenectomy is the treatment of choice for nonparasitic splenic cyst ${ }^{4,10}$ because (1) differentiation of true and false cysts preoperatively does not seem possible ${ }^{14} ;(2)$ as splenomegaly progresses, spontaneous and traumatic ruptures are more likely ${ }^{22}$; (3) elective splenectomy carries a low mortality and morbidity rate in general; (4) it enables the pathologic diagnosis to confirm the clinical diagnosis.

\section{Acknowledgment}

The authors wish to acknowledge Kamini Malhotra, MD, staff pathologist at Fountain Valley Regional Hospital, Fountain Valley, Calif, and Vita Grunded, MD, assistant professor of pathology at the College of Osteopathic Medicine of the Pacific, Pomona, Calif, for their reviews of the pathology case report, and to thank 


\section{Arthur Deleon and Roberto Tarin for the pho- tographic production.}

\section{References}

1. Fowler RH: Cystic tumors of spleen. Int Abstr Surg 1940;70:213-223.

2. Martin JW: Congenital splenic cysts. Am J Surg 1958;96:302. 3. Fowler RH: Hydatid cysts of spleen. Int Abstr Surg 1953;96:105-116.

4. Qureshi MA, Hafner DC, Dorchak JR: Nonparasitic cysts of the spleen. Arch Surg 1964;89:570-574.

5. Pines B, Rabinovitch J: Hemangioma of spleen. Arch Surg 1942;33:487-503.

6. Whitley RD, Winship T: Splenic hemangioma with subsequent fatal hemangiosarcoma. Surgery 1954;35:787-792.

7. Schechter DC, Owen JC, Palmieri AJ: Hemorrhagic cyst of the spleen: Report of two cases. Am J Surg 1962;104:777.

8. Tsakraklides V, Nadlfy TW: Epidermoid cysts of the spleen: A report of five cases. Arch Pathol 1973;96:251-254.

9. Shousha S: Splenic cysts: A report of six cases and a brief review. Postgrad Med J 1978;54:265-269.

10. Fowler RH: Nonparasitic benign cystic tumors of the spleen. Int Abstr Surg 1953;96:209-227.

11. Wortman JA, Norris RP: Splenic cysts: Benign nonparasi- tic cyst of the spleen. $J$ Kans Med Soc 1966;67:355-358.

12. Denehy T, McGrath EW, Breen JL: Splenic rupture and torsion in pregnancy. Obstet Gynecol Surg 1988;43(3):123-131.

13. Rakowski TA, Argy WP, Pierce L Jr, et al: Hypertension by renal compression. JAMA 1977;238:2528-2529.

14. Dachman AH, Ros PR, Murari PJ, et al: Nonparasitic splenic cysts: A report of 52 cases with radiologic-pathologic correlation. AJR 1986;147:537-542.

15. Bron KM, Hoffman WJ: Preoperative diagnosis of splenic cysts. Arch Surg 1971;102:459-461.

16. Bhimji SD, Cooperberg PL, Naiman S, et al: Ultrasound diagnosis of splenic cysts. Radiology 1977;122:787-789.

17. DeMasi CJ, Akdamar K, Sparks RD, et al: Splenic cyst diagnosed by percutaneous needle aspiration and splenography. Am J Dig Dis 1966;11:819-825.

18. Solbati L, Bossi MC, Bellotti E, et al: Focal lesions in the spleen: Sonographic patterns and guided biopsy. AJR 1982;140:59-65.

19. Van Sonnenberg E, Quinn SF, Wittich GR: Interventional radiology in the spleen: Feasibility and safety, abstracted. $R a$ diology 1985;157(P):112.

20. Brande AI, Davis CE, Fierer I: Infectious Disease and Medical Microbiology, ed 2. Philadelphia, Pa, WB Saunders, 1982, p 946.

21. Wilson JF, Rausch RF: Mebendazole and alveolar hydatid disease. Ann Trop Med Parasitol 1982;76(2):165-173.

22. Qureshi MA, Hafner CD: Clinical manifestations of splenic cysts: Study of 75 cases. Am Surg 1965;31:605-608. 
